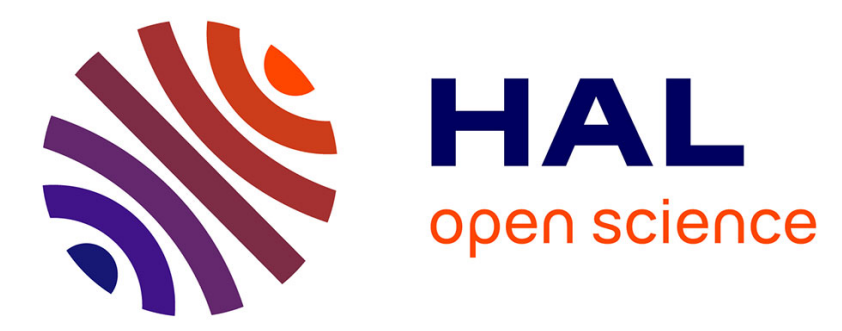

\title{
Plasticity and cerebral reorganization: an update
}

Monica N Toba, Emmanuel J. Barbeau

\section{To cite this version:}

Monica N Toba, Emmanuel J. Barbeau. Plasticity and cerebral reorganization: an update. Revue Neurologique, 2021. hal-03443238

\section{HAL Id: hal-03443238 \\ https://hal.science/hal-03443238}

Submitted on 23 Nov 2021

HAL is a multi-disciplinary open access archive for the deposit and dissemination of scientific research documents, whether they are published or not. The documents may come from teaching and research institutions in France or abroad, or from public or private research centers.
L'archive ouverte pluridisciplinaire HAL, est destinée au dépôt et à la diffusion de documents scientifiques de niveau recherche, publiés ou non, émanant des établissements d'enseignement et de recherche français ou étrangers, des laboratoires publics ou privés. 


\section{Plasticity and cerebral reorganization: an update}

More than 100 years ago, Ramon y Cajal, one of the founding fathers of modern neuroscience, suggested in Degeneration and Regeneration of Nervous System that 'nerve paths are something fixed, ended, and immutable [...] everything may die, nothing may be regenerated' (y Cajal, 1991). Cajal's view dominated the young field of neuroscience for a long period until researchers reached one of the most outstanding and promising conclusions regarding the adult brain: that it is, in fact, plastic. It is constantly being reshaped by experience but can also undergo significant reorganization in the face of aging and pathological assault. This has sparked a tremendous number of studies, and hope, to decipher and promote brain plasticity.

The current understanding of human brain plasticity and its underlying mechanisms is based on advanced technologies allowing to visualize the brain and manipulate neuronal activity with great precision. As a result, various functional and structural plasticity forms have been described, going from the molecular to the neural network level, occurring over a wide range of time scales. However, many questions remain unanswered. Updates are necessary to establish what has been done and learned to date and what remains to be done. In this context, the joint 2021 meeting of the Groupe de Réflexion sur les Evaluations Cognitives (GRECO) and Société de Neuropsychologie de Langue Française (SNLF), hosted by the annual conference of the Journées de Neurologie de Langue Française (JNLF), organized a whole day dedicated to "Plasticity and Cerebral Reorganization". This meeting aimed to focus on recent key experimental findings, different methodological approaches, and their clinical applications. The present special issue of La Revue Neurologique is a synthesis of the work presented in this framework.

The first article reviews neuroplasticity from the perspective of intraoperative electrical mapping combined with neuropsychological perioperative data and neuroimaging (Duffau, 2021). After a review of data challenging classical localizationist models, mechanisms of neuroplasticity are discussed in the functional connectome framework. Implications for neurosurgical interventions, the creation of new atlases, and the neuro-rehabilitation of brain-damaged patients are also presented. In particular, this article discusses the relevancy for the field of plasticity of the concept of 'meta-network' (i.e., networks of networks, see also Herbet \& Duffau, 2020), which represents the result of interactions between and within brain networks during complex cognitive demanding tasks. Meta-networks involve transitory, taskinduced changes between brain regions encompassing specialized functional systems (Cocchi, Zalesky, Fornito, \& Mattingley, 2013) and imply the existence of cortical nodes with highly connective properties 
essential for cross-network integration (de Pasquale, Della Penna, Sporns, Romani, \& Corbetta, 2016; Herbet \& Duffau, 2020).

The same network perspective is promoted in the article by Bartolomeo (2021) that uses visual neglect as a model to study cerebral plasticity and specifically addresses the issue of adaptive and maladaptive reorganization of neurocognitive brain networks in brain-damaged patients. Potential factors influencing post-stroke recovery of neglect and their biomarkers are emphasized. On the one hand, the role of the localization of the lesion in compensatory plasticity is emphasized, with a particular focus on white matter integrity within and between hemispheres (see for details Bartolomeo, Thiebaut de Schotten, \& Doricchi, 2007; Lunven et al., 2015; Nyffeler et al., 2019; Thiebaut de Schotten et al., 2005; Toba et al., 2018; Toba et al., 2020; Toba et al., 2017; Urbanski et al., 2011). On the other hand, critical time windows of plasticity and corresponding mechanisms are presented and illustrated with protocols stimulating brain plasticity through prism adaptation in patients with neglect (Lunven et al., 2019), among other examples.

The role of new technologies is further illustrated in the article by Ben Hamed et al. (2021) that presents a comprehensive overview of neurofeedback, a cognitive training tool with promising results in improving brain functions, which combines behavioral training with directed control of cortical signals. The methodological principles and behavioral benefits of neurofeedback and its role in triggering brain plasticity (changes in both grey and white matter properties and functional connectivity) are extensively presented. Neurofeedback has been used in healthy participants to enhance cognitive functions and in patients (see for details Table 1 in Ben Hamed et al., 2021) to restore specific cognitive functions such as in attention deficit hyperactivity disorders (ADHD), anxiety, depression, and post-traumatic stress disorder. This article also has the merit to emphasize several limitations of neurofeedback, such as the transfer of behavioral effects outside the research context, the problem of experimental controls, and differences between responders and non-responders.

In this special issue, both plasticity following limb amputation and plasticity-related to hearing losses are also reviewed. Raffin et al. (2021) report various forms of sensorimotor plasticity following limb amputation and insist on two post-amputation frameworks, i.e., plasticity triggered by deprivation (including models such as maladaptive plasticity and persistent representation) and use-dependent plasticity. Plasticity outside the primary sensorimotor cortex is also presented, and the link between theoretical models and new therapeutic strategies for phantom limb pain is discussed. Complementarily, the notion of maladaptive plasticity introduced in the review article by Bartolomeo (2021) and linked to 
post-stroke recovery is here developed in relation to phantom limb pain intensity (Birbaumer et al., 1997; Flor, Denke, Schaefer, \& Grusser, 2001) that could be explained by the expansion of body parts representations adjacent to the missing limb representations in the deprived cortex. Clinical applications targeting sensorimotor plasticity as a mean of decreasing phantom limb pain include the use of myoelectric prosthesis (Ortiz-Catalan et al., 2016), mirror therapy (Ramachandran \& RogersRamachandran, 1996), sensory stimulation (Flor et al., 2001), and non-invasive brain stimulation (either transcranial magnetic stimulation or transcranial direct current stimulation) (Nardone et al., 2019) that are also further presented in the review paper by Raffin et al. (2021).

The article by Barone et al. (2021) introduces cross-modal and intra-modal plasticity in relation to symmetric and asymmetric hearing losses. The restoration of hearing loss using cochlear implantation and its behavioral, anatomical, and functional consequences are developed. 'Compensatory plasticity', referring to modified brain dynamics subtending adaptive modifications following pathology (see Rauschecker, 1995), is nicely illustrated here. The authors provide relevant examples illustrating how these "compensatory" mechanisms influence cortical reorganization (Lasfargues-Delannoy, Strelnikov, Deguine, Marx, \& Barone, 2021; Rouger et al., 2007). Clinical applications reported in this review include the restoration of symmetric (bilateral) and asymmetric hearing after cochlear implantation with effects mainly on auditory perception and audiovisual integration. It is suggested that a strong visual and audiovisual based rehabilitation during the first months after implantation can improve the recovery of speech intelligibility (Strelnikov et al., 2009). In contrast, the concept of maladaptive plasticity is illustrated by the case of the invasion of the auditory cortex by visual functions during the restoration of hearing with cochlear implants (Ambert-Dahan et al., 2017). The authors also suggest potential improvements in estimating brain plasticity.

We intended with this special issue to cover a large number of forms of brain plasticity, in the human mainly, in order to provide a multifaceted perspective of the current research in the field. We sincerely hope that this special issue will stimulate new research and inspire further work showing the extent to which the brain can change. This endeavor is critical for patients with brain pathologies.

\section{References:}

Ambert-Dahan, E., Giraud, A. L., Mecheri, H., Sterkers, O., Mosnier, I., \& Samson, S. (2017). Emotional recognition of dynamic facial expressions before and after cochlear implantation in adults with progressive deafness. Hear Res, 354, 64-72. doi:10.1016/j.heares.2017.08.007 
Bartolomeo, P. (2021). From competition to cooperation: Visual neglect across the hemispheres. Rev Neurol (Paris). doi:10.1016/j.neurol.2021.07.015

Bartolomeo, P., Thiebaut de Schotten, M., \& Doricchi, F. (2007). Left unilateral neglect as a disconnection syndrome. Cereb Cortex, 17(11), 2479-2490. Retrieved from http://www.ncbi.nlm.nih.gov/pubmed/17272263

Birbaumer, N., Lutzenberger, W., Montoya, P., Larbig, W., Unertl, K., Topfner, S., . . Flor, H. (1997). Effects of regional anesthesia on phantom limb pain are mirrored in changes in cortical reorganization. $J$ Neurosci, 17(14), 5503-5508. Retrieved from https://www.ncbi.nlm.nih.gov/pubmed/9204932

Cocchi, L., Zalesky, A., Fornito, A., \& Mattingley, J. B. (2013). Dynamic cooperation and competition between brain systems during cognitive control. Trends Cogn Sci, 17(10), 493-501. doi:10.1016/j.tics.2013.08.006

de Pasquale, F., Della Penna, S., Sporns, O., Romani, G. L., \& Corbetta, M. (2016). A Dynamic Core Network and Global Efficiency in the Resting Human Brain. Cereb Cortex, 26(10), 4015-4033. doi:10.1093/cercor/bhv185

Duffau, H. (2021). The death of localizationism: The concepts of functional connectome and neuroplasticity deciphered by awake mapping, and their implications for best care of braindamaged patients. Rev Neurol (Paris). doi:10.1016/j.neurol.2021.07.016

Flor, H., Denke, C., Schaefer, M., \& Grusser, S. (2001). Effect of sensory discrimination training on cortical reorganisation and phantom limb pain. Lancet, 357(9270), 1763-1764. doi:10.1016/S0140-6736(00)04890-X

Herbet, G., \& Duffau, H. (2020). Revisiting the Functional Anatomy of the Human Brain: Toward a Meta-Networking Theory of Cerebral Functions. Physiol Rev, 100(3), 1181-1228. doi:10.1152/physrev.00033.2019

Lasfargues-Delannoy, A., Strelnikov, K., Deguine, O., Marx, M., \& Barone, P. (2021). Supra-normal skills in processing of visuo-auditory prosodic information by cochlear-implanted deaf patients. Hear Res, 410, 108330. doi:10.1016/j.heares.2021.108330

Lunven, M., Rode, G., Bourlon, C., Duret, C., Migliaccio, R., Chevrillon, E., . . Bartolomeo, P. (2019). Anatomical predictors of successful prism adaptation in chronic visual neglect. Cortex, 120, 629641. doi:10.1016/j.cortex.2018.12.004

Lunven, M., Thiebaut De Schotten, M., Bourlon, C., Duret, C., Migliaccio, R., Rode, G., \& Bartolomeo, P. (2015). White matter lesional predictors of chronic visual neglect: a longitudinal study. Brain, 138(Pt 3), 746-760. doi:10.1093/brain/awu389

Nardone, R., Versace, V., Sebastianelli, L., Brigo, F., Christova, M., Scarano, G. I., . . Sellner, J. (2019). Transcranial magnetic stimulation in subjects with phantom pain and non-painful phantom sensations: A systematic review. Brain Res Bull, 148, 1-9. doi:10.1016/j.brainresbull.2019.03.001

Nyffeler, T., Vanbellingen, T., Kaufmann, B. C., Pflugshaupt, T., Bauer, D., Frey, J., . . . Cazzoli, D. (2019). Theta burst stimulation in neglect after stroke: functional outcome and response variability origins. Brain, 142(4), 992-1008. doi:10.1093/brain/awz029

Ortiz-Catalan, M., Guethmundsdottir, R. A., Kristoffersen, M. B., Zepeda-Echavarria, A., CaineWinterberger, K., Kulbacka-Ortiz, K., . . . Hermansson, L. (2016). Phantom motor execution facilitated by machine learning and augmented reality as treatment for phantom limb pain: a single group, clinical trial in patients with chronic intractable phantom limb pain. Lancet, 388(10062), 2885-2894. doi:10.1016/S0140-6736(16)31598-7

Ramachandran, V. S., \& Rogers-Ramachandran, D. (1996). Synaesthesia in phantom limbs induced with mirrors. Proc Biol Sci, 263(1369), 377-386. doi:10.1098/rspb.1996.0058

Rauschecker, J. P. (1995). Compensatory plasticity and sensory substitution in the cerebral cortex. Trends Neurosci, 18(1), 36-43. doi:10.1016/0166-2236(95)93948-w

Rouger, J., Lagleyre, S., Fraysse, B., Deneve, S., Deguine, O., \& Barone, P. (2007). Evidence that cochlear-implanted deaf patients are better multisensory integrators. Proc Natl Acad Sci U S A, 104(17), 7295-7300. doi:10.1073/pnas.0609419104 
Strelnikov, K., Rouger, J., Lagleyre, S., Fraysse, B., Deguine, O., \& Barone, P. (2009). Improvement in speech-reading ability by auditory training: Evidence from gender differences in normally hearing, deaf and cochlear implanted subjects. Neuropsychologia, 47(4), 972-979. doi:10.1016/j.neuropsychologia.2008.10.017

Thiebaut de Schotten, M., Urbanski, M., Duffau, H., Volle, E., Levy, R., Dubois, B., \& Bartolomeo, P. (2005). Direct evidence for a parietal-frontal pathway subserving spatial awareness in humans. Science, 309(5744), 2226-2228. doi:10.1126/science.1116251

Toba, M. N., Migliaccio, R., Batrancourt, B., Bourlon, C., Duret, C., Pradat-Diehl, P., . . Bartolomeo, P. (2018). Common brain networks for distinct deficits in visual neglect. A combined structural and tractography MRI approach. Neuropsychologia, 115, 167-178. doi:10.1016/j.neuropsychologia.2017.10.018

Toba, M. N., Zavaglia, M., Malherbe, C., Moreau, T., Rastelli, F., Kaglik, A., . . Valero-Cabré, A. (2020). Game theoretical mapping of white matter contributions to visuospatial attention in stroke patients with hemineglect. Hum. Brain Mapp., 41(11), 2926-2950. doi:10.1002/hbm.24987

Toba, M. N., Zavaglia, M., Rastelli, F., Valabregue, R., Pradat-Diehl, P., Valero-Cabre, A., \& Hilgetag, C. C. (2017). Game theoretical mapping of causal interactions underlying visuo-spatial attention in the human brain based on stroke lesions. Hum Brain Mapp. doi:10.1002/hbm.23601

Urbanski, M., Thiebaut de Schotten, M., Rodrigo, S., Oppenheim, C., Touze, E., Meder, J. F., . . . Bartolomeo, P. (2011). DTI-MR tractography of white matter damage in stroke patients with neglect. Exp Brain Res, 208(4), 491-505. doi:10.1007/s00221-010-2496-8

y Cajal, S. R. (1991). Cajal's degeneration and regeneration of the nervous system (Vol. No. 5). Oxford: Oxford University Press.

Monica N. Toba ${ }^{1}$ and Emmanuel J. Barbeau ${ }^{2}$

${ }^{1}$ Laboratory of Functional Neurosciences (UR UPJV 4559), University Hospital of Amiens and University of Picardie Jules Verne, Amiens, France

${ }^{2}$ Centre de Recherche Cerveau et Cognition (CerCo), UMR5549, CNRS - Université de Toulouse, France

E-mail addresses:

monica.n.toba@gmail.com

emmanuel.barbeau@cnrs.fr 